\title{
Arbor
}

\section{La comunidad reconocida: familias, escuelas, y regantes y vecinos}

\author{
J. José García de la Cruz Herrero y Evaristo Prieto Navarro
}

Arbor CLXV, 652 (Abril 2000), 639-655 pp.

En este trabajo se estudia la intervención del Derecho en la comunidad. Se parte de una definición social de comunidad rechazando como tales aquellas que el Derecho llama comunidades pero no lo son socialmente. El Derecho interviene en las comunidades como la familia, pero lo hace pensando esencialmente en los individuos que la componen no en la comunidad social como tal. El diseño individualista del Derecho occidental vigente impide o, incluso, produce consecuencias no buscadas cuando el Derecho actúa sobre comunidades sociales.

\section{Comunidades reconocidas}

¿Qué entendemos por comunidades reconocidas? En las sociedades modernas los seres humanos vivimos moviéndonos y movidos por una compleja red de grupos, instituciones, corporaciones y relaciones humanas muy variadas. Entre todas ellas las comunidades pueden ser descritas como aquellos grupos humanos en el que se produce esencialmente un tipo de relaciones directas, emocionales y afectivas. A su vez, dentro de este tipo de agrupaciones algunas son reconocidas, es decir, intervenidas explícitamente por el Derecho en algún aspecto de su actividad social. En este trabajo vamos ha considerar como comunidades reconocidas aquellas que siéndolo de hecho, esto es, socialmente, al mismo tiempo tienen algún grado de formalización jurídica positiva.

Por lo tanto quedan fuera de nuestro objetivo, por un lado, aquellas figuras que el Derecho considera comunidades, pero sociológicamente no 


\section{J. José García de la Cruz Herrero y Evaristo Prieto Navarro}

lo son, al menos, a nuestro juicio, y, por el otro, todas aquellas comunidades que lo son de hecho, pero al margen de un marco jurídico regulador específico para ellas.

El cruce, la suma, de estos dos criterios nos permite descabalgar directamente algunas figuras jurídicas que sin duda sólo cumplen una de las dos condiciones, nos referimos a las figuras jurídicas que encauzan las actividades de propietarios (comunidades de bienes ${ }^{1}$ ), propiedades especiales o sociedades ${ }^{2}$, su clara mercantilización, su fin de lucro ${ }^{3}$, nos permite considerarlas asociaciones ${ }^{4}$. Por el otro lado, no abordaremos todas aquellas comunidades de hecho en las que no interviene el Derecho en sus aspectos sociales, nos referimos a esos grupos humanos afectivos, esencialmente amigos y compañeros.

\section{Derecho y comunidad}

Aunque en el último apartado de este trabajo realizamos un repaso de las virtudes y perversiones del Derecho sobre la vida cotidiana de las comunidades (colonización del mundo de vida), parece conveniente anticipar algunos rasgos de nuestra posición analítica.

La revolución burguesa contra el Antiguo Régimen produce un Derecho construido sobre la dicotomía individuo-nación ${ }^{5}$. Por supuesto esta obsesión del poder burgués por la figura del individuo como núcleo y esencia de la sociedad ha generado grandes vacíos entre la realidad social (claramente grupal y asociativa) con el marco jurídico y productivo del sistema liberal y capitalista ${ }^{6}$. Estos huecos han sido rellenados, tarde y bajo presión, por el marco jurídico en lo asociativo ${ }^{7}$ (libertad de asociación, sindicatos, partidos, etc.), pero ha quedado en unos casos abandonado y en otros bajo el imperialismo individualista el ámbito comunitario.

Las comunidades de hecho, los grupos humanos estables, han sido zarandeados por dos grandes fuerzas, el sistema productivo capitalista liberal e individualista, y el marco jurídico que inicialmente estuvo al servicio y posteriormente se ha convertido en la principal palanca de contención del insaciable hambre del individualismo liberal económico ${ }^{8}$. En este trabajo no ignoramos la interdependencia, cuando no, dependencia del sistema jurídico respecto al productivo ${ }^{9}$. Sin embargo, vamos a prescindir de esa relación de lo jurídico con el modo de producción capitalista, centrándonos exclusivamente en la relación entre el Derecho y la vida grupal en tres tipos de comunidades (por supuesto esta evasión de nuestro argumento sobre la interdependencia con lo económico, sólo es 
La comunidad reconocida: familias, escuelas, y regantes...

una licencia analítica que nos ha de permitir enfocar lo jurídico, queda abierto totalmente el debate sobre la intrumentalidad de éste).

Pasamos ahora a nuestra exposición. Juan y María, nuestros dos protagonistas germinales, se quieren, y tras un tiempo de noviazgo, por supuesto con algunas discusiones, deciden formar una familia.

Como todos sabemos esta decisión no se resuelve cogiéndose de la mano y construyendo una cabaña debajo de un manzano. Se encuentran con diversos requisitos jurídicos y administrativos, que por un lado les obligarán ha protagonizar rituales jurídicos y administrativos (además, de los religiosos que correspondan) y por otro les impide lo de la cabaña en el manzano.

Supongamos que Juan y María quieren tener hijos, adquirir una casa $y$, por supuesto, que sus hijos reciban una educación adecuada. Ya tenemos alguno de nuestros objetivos encarnados en nuestros dos protagonistas: 1) Familia; 2) Escuela; y 3) Vecinos (al comprar su casa).

El hilo argumental del trabajo partirá de la intervención del Derecho en las acciones y reacciones de Juan y María cuando sus vidas se adentran en ese tipo de comunidades. El primer nivel de análisis lo situaremos en el Derecho positivo vigente en España al que sumaremos los problemas que genera la juridificación de ese mundo de vida.

\section{La comunidad familiar}

Cuando dos personas, Juan y María en nuestro caso, hablan y deciden conformar una familia, el proceso desgaja a dos miembros de dos familias ya conformadas para generar una nueva. Desde el punto de vista sociológico estamos enlazando dos grupos familiares entre sí a través del esfuerzo por poner en marcha una tercera familia, en la que, normalmente, pondrán sus fuerzas las tres familias.

La primera intervención del Derecho en la dinámica de construcción de una nueva familia se realiza mediante el monopolio de la Administración Pública (generalmente la Administración de Justicia) para determinar la existencia o no de una familia, matrimonio como acto público y solemne, que en el caso español puede elegirse entre la forma religiosa y la civil.

A la vía matrimonial canónica el Código Civil le dedica varios artículos, así, el artículo 63 establece que «la inscripción del matrimonio celebrado en España de forma religiosa se practicará con la simple presentación de la certificación de la Iglesia...». De esta manera, el Derecho interviene en una de las primeras discusiones privadas ${ }^{10}$ de Juan y Ma- 


\section{J. José García de la Cruz Herrero y Evaristo Prieto Navarro}

ría, una pareja en vía de contraer matrimonio: ¿por lo civil? ¿Por lo religioso (aquí canónico)? O, no nos casamos, ¿pareja de hecho (sin pape$\left.\operatorname{les}^{11}\right)$ ?

El marco legilsativo da más entidad a los matrimonios civil y canónico, marginando la pareja de hecho como una comunidad de lazos más débiles. Hacemos referencia a la fuerza en la España más tradicional de la idea de que el civil es un matrimonio light ${ }^{12}$. Naturalmente esta cognición está especialmente arraigada entre las generaciones mayores y católicas que rechazan frontalmente esta práctica.

La tercera fórmula la «pareja de hecho», «familia de hecho» (los sin papeles), tiene una historia jurídica posconstitucional curiosa cuando no ejemplar.

La Constitución Española (año 1978) no las considera explícitamente, pero tampoco las prohibe o rechaza. El amparo jurídico a esta fórmula tiene su principal palanca de apoyo en una sentencia del Tribunal Supremo (18 de mayo de 1992) en la que éste establece algunas condiciones para que las parejas de hecho puedan generar la aplicación de la normativa legal. Esto por supuesto tiene su cara y su cruz, el anverso lo constituyen las posibilidades que se les abre a estas comunidades, hasta ese momento no reconocidas, para utilizar alguno de los resortes jurídicos que están al servicio de la familia en general. El reverso está en las condiciones de mínimos que enuncia el alto tribunal para considerar una pareja de hecho como tal ${ }^{13}$.

Más allá del poder jurisdiccional de esta sentencia del TS la legislación española considera la familia de hecho como una más en materia de adopción (Ley de 11 de noviembre de 1987), en materia de arrendamiento (Ley de Arrendamientos Urbanos de 24 de noviembre de 1994), por cierto, una ley que se ha desarrollado hasta alcanzar la realidad social de una comunidad de hecho, al equiparar el cónyuge del arrendatario a la persona que hubiere venido viviendo con el arrendatario de forma permanente en análoga relación de afectividad, «con independencia de su orientación sexual».

Recapitulando, el Derecho ofrece tres vías para generar una familia, dos de ellas totalmente protegidas, y la tercera $u$ otras alternativas, menos o nada amparadas. Si prescindimos de los casos que por razones legales o religiosas no pueden acceder a las dos vías reconocidas por el Código Civil. En el resto, la inmensa mayoría de las decisiones de las futuras parejas, la elección entre las tres vías es producto de una complicada interacción grupal, en la que intervienen, por lo menos, las dos familias de origen (directa o indirectamente ${ }^{14}$ ) y, naturalmente, los dos miembros de la pareja ${ }^{15}$. Todos sabemos que si una de las familias de ori- 
La comunidad reconocida: familias, escuelas, y regantes...

gen es «fundamentalista» en sus principios religiosos o anti-religiosos, con gran probabilidad determinará la vía de matrimonio que dará origen a la nueva familia.

De esta manera, el Derecho interviene, al consagrar como ritual público el matrimonio (tanto civil como canónico), impidiendo o dificultando la privacidad de la decisión de Juan y María, en contraste, por ejemplo, con la escritura de un piso, la formalización de un testamento, que hoy por hoy, no implican un ritual público, basta con la fe pública de un notario.

El segundo gran escenario de la vida familiar en el que interviene el Derecho es en las relaciones de poder entre los miembros de las familias. Todas las familias, como la mayoría de los grupos y comunidades, se conforman de modo asimétrico y desequilibrado entre sus miembros. Esto es, que la configuración del nuevo grupo social se fraguará en distintos escenarios en los que, normalmente, diferentes miembros del grupo tendrán, ejercerán variados grados de poder social. Hablamos de asuntos tan cotidianos como el reparto de labores domésticas, costumbres higiénicas, hábitos alimenticios, de horarios, vinculación con la familia de origen, actividades de ocio, responsabilidades o gestión económica, objetivos materiales, educación de los hijos, etc.

La segunda intervención del Derecho se ha dirigido ha regular estas relaciones asimétricas, normalmente a limitarlas, y para ello el Derecho interviene en dos sentidos:

a) Generando deberes y derechos más allá o más acá de los que espontáneamente hayan surgido en cada grupo familiar (las comunidades familiares son realidades hetereogéneas, nunca encontraremos dos familais iguales), aquí incluiríamos los típicos deberes de filiación y paternidad. Así, «El padre y la madre, aunque no ostenten la patria potestad, están obligados a velar por los hijos menores y a prestarles alimentos» (artículo 110 Código Civil), o siguiendo con las relaciones paterno-filiales a «velar por ellos, tenerlos en su compañía, alimentarlos, educarlos y procurarles una formación integral» (CC artículo 154.1).

De esta manera podríamos seguir enumerando diversos preceptos que regulan las relaciones entre los cónyuges y entre padres e hijos. Por supuesto, la intervención real del Derecho en este tipo de dinámica grupal se realiza sólo en casos especiales, y siempre, sin capacidad de regenerar el grupo familiar. Esto es, que cuando unos padres no velan por sus hijos en la medida que sus posibilidades económicas y de salud se lo permiten, en esos supuestos el Derecho no interviene para regenerar el grupo, sino para desmembrarlo definitivamente, en unas ocasiones como consecuencia no buscada de su intervención, y en otras explícitamente 


\section{J. José García de la Cruz Herrero y Evaristo Prieto Navarro}

como solución quirúrgica, normalmente, buscando la salida a los miembros individuales (hijos) fuera de su grupo familiar actual.

b) Limitando los abusos de poder por parte de un miembro de la familia respecto a cualquier otro. Así, siguiendo con tema filio-paternal dice la normativa que «si los hijos tuvieren suficiente juicio deberán ser oídos siempre antes de adoptar decisiones que les afecten» o cuando dice «los padres... Podrán también corregir razonable y moderadamente a los hijos» (CC 154.2). ¿Cuándo los padres oyen y hacen caso a sus hijos, en el mejor de los casos juiciosos, pero jóvenes? ¿Cómo puede o pretende intervenir el Derecho en relaciones tan informales y privadas? En cualquier caso, la potencial discrepancia entre hijos y padres queda perfectamente canalizada y zanjada por la ley cuando dice: «Los padres podrán en el ejercicio de su potestad recabar el auxilio de la autoridad». (CC artículo 154.2).

El segundo aspecto en el que más desequilibrio se ha observado ha sido en el papel subordinado de la mujer, asimetría respaldada legalmente de forma total hasta 1975 en España (reforma del Código Civil por la Ley 14/1975, de 2 de mayo). Situación que legalmente se rompe con la Constitución (1978) y la Ley 11/1981, de 13 mayo, que modificó las situaciones de desequilibrio entre cónyuges, que posteriormente se ha refrendado por la Ley 11/1990, de 15 de octubre, que aborda el principio de no discriminación por razón de sexo.

Por supuesto, estos cambios normativos impiden la utilización del Derecho para ejercer un poder social prevalente del varón sobre la mujer (paralelo al filial, artículo $154.2 \mathrm{CC}$ ), en este aspectto no se le puede negar al Derecho su capacidad de eliminar, no retroactivamente, los males que genera la aplicación de una normativa desfasada y anacrónica (por ejemplo la despenalización del adulterio y el amancebamiento, Ley 2/1978, de 26 de mayo). Sin embargo, los feudos familiares no han desaparecido.

Los desequilibrios, la asimetría entre cónyuges en el seno familiar no han acabado. El reparto de labores domésticas, el poder de decisión en asuntos familiares, y la dependencia económica siguen ahí, y hoy por hoy, la sociedad tiene que hacer mucho para amortiguar esas asimetrías en los senos familiares.

Empezando por esta asimetría, en las últimas investigaciones sobre la familia española se observa un cambio de tendencia gracias a la incorporación de la mujer al trabajo, y sobre todo al sistema educativo, lo que ha permitido dejar «fuera de juego» la fórmula patriarcal más tradicional $^{16}$.

En el segundo ámbito de asimetría, la toma de decisiones, las familias españolas han sido distribuidas de la siguiente manera: Familias patriarcales $9 \%$; matriarcales $10 \%$ y simétricas un $60 \%$. Las cifras patriar- 
La comunidad reconocida: familias, escuelas, y regantes...

cado y matriarcado son muy diferentes, las primeras indican una situación familiar claramente tradicional, la segunda está basada en un liderazgo de la mujer esencialmente en dos ámbitos: los colegios de los hijos y la compra de equipos y bienes domésticos ${ }^{17}$. En general la asimetría en este ámbito familiar es acumulativa, esto es, que cuando uno de los cónyuges se muestra claramente poderoso o líder en un área de decisiones suele serlo en otros, acumula.

Finalmente, la división del trabajo en el hogar cambia esencialmente empujada, allí donde existe, por el trabajo extradoméstico de la mujer. Aunque, esta palanca materialista es importante, la base del cambio está en los modelos de los roles de género de los varones, proceso, por supuesto ajeno al Derecho.

Mención aparte merece el tema de la violencia doméstica, entre cónyuges o respecto a los hijos. Aquí sí estamos ante una intervención del Derecho penal, aunque, normalmente lo hace como elefante en cacharrería, provocando en el mejor de los casos la desmembración del grupo. El diseño del Derecho penal no está preparado para tratar con grupos hu$\operatorname{manos}^{18}$. ¿Qué capacidad y utilidad tiene un juez o una normativa equilibradora en un ámbito tan intimo y privado como el hogar? En todos estos casos el Derecho interviene salvaguardando (pensando en...) a los individuos, salvándolos o sacándolos de un grupo que estaba perjudicando a uno de los miembros, por supuesto a un individuo abstracto ${ }^{19}$ (una entidad jurídica que supone que un ser humano es algo independiente de su interdependencia social). Sin embargo, estamos ante una comunidad que se conforma precisamente en el desequilibrio, la generosidad de unos y las necesidades de otros, en fin en el afecto y la idea de grupo.

Sorprendentemente la casi totalidad de la legislación sobre familia ignora o subestima los aspectos grupales y sobrevalora e interviene en ámbitos individuales, provocando paradojas sociales, al intervenir formalmente sobre miembros individuales de una familia, que en la mayoría de los casos pertenecen o dependen afectivamente de un amplio grupo familiar en el que participan, hijos (nietos), padres, abuelos y tíos (hermanos). Estamos seguros que si uniéramos al poder de un juzgado las consideraciones de un psicólogo social (experto en dinámica de grupo) en la mayoría de las ocasiones, si la legislación lo permitiera, las intervenciones jurisdiccionales serían sobre el grupo, potenciando o respaldando papeles familiares que sí tienen valor en la intimidad y privacidad de los hogares familiares, como los abuelos, los tíos o amigos íntimos del grupo familiar.

El tercer ámbito de intervención, en el que más se extiende el Derecho de familia es el patrimonial. Aquí, el Derecho se dedica a salvaguar- 


\section{J. José García de la Cruz Herrero y Evaristo Prieto Navarro}

dar a los propietarios individuales dentro de una comunidad, esto es, que siempre está diseñado para dividir la tarta (todo el patrimonio) entre los miembros, individuales, de esa comunidad familiar. Parece que este principio es contra la naturaleza de la esencia comunitaria. De nuevo la legislación vigente y hegemónica en nuestros dias está determinada por su origen individualista y liberal (y el sacramento de la propiedad como esencia de la ciudadanía moderna occidental ${ }^{20}$ ).

Así llama la atención que en los procesos de separación la legislación prevea y obligue a la presencia, asesoramiento, de un letrado, a un periodo de separación, y no obligue a la intervención de psicólogos de familia y trabajadores sociales. ¿Qué es más importante? ¿La división del patrimonio o la posibilidad de dar continuidad algunos lazos de relaciones sociales entre los miembros de una familia? Por supuesto, muchas familias, tras un proceso de separación y divorcio mantienen sanas relaciones de ayuda mutua, excónyuges que se tratan como dos viejos amigos, pero en esas situaciones no sólo no ha intervenido el Derecho, al contrario, normalmente se han alcanzado a pesar de los desaguisados a los que obliga el Derecho y los tribunales. Seguramente esta es una de las razones del éxito de la mediación familiar como camino alternativo o complementario en procesos de ruptura o crisis de una comunidad familiar.

\section{La escuela}

Los colegios e institutos son las dos figuras sobre las que se debería generar la comunidad que hemos denominado escuela. Nuestra observación es que en España las escuelas, cada centro escolar, da origen a diversas comunidades o seudocomunidades (no lo son, pero lo parecen). Por un lado está el estamento o colectivo de profesores, dentro de él, el grupo de dirección, por otro lado, nos encontramos a los alumnos, cada clase conforma un agregado administrativo, y finalmente, fuera, pero con influencia encontramos a los padres, de cada alumno o alumna, o su Asociación de Padres (APAs).

Ningún colegio o un instituto español conforma una comunidad de hecho. Los órganos que dan unidad e identidad a estos centros son cargos de gestión educativa. Los Consejos Escolares de los Centros son más parecidos a una Junta de Propietarios de vecinos que a una reunión, asamblea, de afectados o interesados por la educación.

Dentro del seno escolar hay dos colectivos con más posibilidades de constituir comunidades; uno es el claustro de profesores; y el otro, los 
La comunidad reconocida: familias, escuelas, y regantes...

alumnos que conforman cada clase, grupo escolar. Pero, los primeros están ligados al centro por su actividad laboral, bastante homogeneizada desde el exterior ${ }^{21}$, y los segundos están bajo el liderazgo y autoridad de profesores y padres. Sin duda son los alumnos los que están más cerca de la idea de comunidad, aunque en la práctica configuran su vida social en pequeños grupos de amigos, siendo su adscripción a una clase un asunto administrativo (por apellido o edades).

En cualquier caso resaltamos la incapacidad del Derecho, la normativa vigente en España, para generar comunidades educativas, objetivo que se planteo explícitamente hace ya más de 14 años.

Los colectivos que conforman esas teóricas comunidades educativas no han entrado en esa dinámica incentivada. Tras catorce años de vigencia de una legislación que abre las puertas de los centros escolares, éstos son menos comunidad que nunca, en todo caso se han desarrollado pequeños grupos (¿oligarquías?) de padres y profesores que combaten 0 colaboran por ciertas mejoras o beneficios para el centro educativo ${ }^{22}$.

La dinámica cotidiana de estos centros está lejos, incluso, de la idea más suave y difusa de comunidad. Hoy por hoy, los centros escolares son un servicio público o privado que relaciona a un grupo de gestores educativos con cada familia, padres de un alumno o alumna concreto, que no se conocen personalmente entre sí. Por otro lado, la legislación que teóricamente ha querido la creación de comunidades educativas, no ha permitido que las cosas importantes de la vida diaria y anual de los centros escolares se decidan allí. Estamos hablando, desde la incorporación o la salida de un profesor al diseño de un curso (curricular), las dotaciones de materiales, la admisión de alumnos, todo es decidido por el Ministerio o la Consejería encargada. Por supuesto que esta homogeneización impide dramáticos desfases y desequilibrios en la formación, al menos, de los centros públicos y concertados, pero, inevitablemente vacían de contenido real y fundamental a los centros escolares a la hora de conformar comunidades educativas.

\section{Comunidad de regantes y vecinos}

La primera pregunta es ¿en qué medida son estas comunidades, hoy en día, comunidades sociales de hecho? Respecto a las primeras, comunidades de regantes, el no es rotundo, estamos claramente ante un tipo de asociación de interés que no ofrece dudas en su evaluación.

En contraste, la comunidad de vecinos permite matices, aunque, los asuntos económicos monopolicen en la práctica este tipo de figuras jurí- 


\section{J. José García de la Cruz Herrero y Evaristo Prieto Navarro}

dicas, de hecho la comunidad de vecinos jurídicamente es denominada Junta de Propietarios (sobran explicaciones). No obstante, la vecindad sí genera, o al menos, de vez en cuando permite relaciones comunitarias entre vecinos. Desde esta perspectiva, las relaciones vecinales generan una comunidad de hecho, y el Derecho interviene especialmente en aquellos ámbitos de propiedad horizontal (propiedad privativa de los pisos y copropiedad sobre los elementos comunes), en relaciones vecinales en edificios, esto es, un edificio dividido en pisos o locales susceptibles de aprovechamiento independiente, pero que llevan inherentes unos elementos comunes, y una pluralidad de propietarios, a quienes pertenecen los distintos pisos o locales (véase la Ley de Propiedad Horizontal del 6 de abril de 1999).

Las Juntas de Propietarios intervienen en asuntos como modificación de elementos arquitectónicos, instalaciones comunes, mantenimiento del edificio, y sobre todo, en el cobro y gestión de las cuotas a los propietarios. Además, están facultadas para redactar unos «reglamentos de régimen interior» que regulan los detalles de la convivencia y la adecuada utilización de los servicios y cosas comunes. Asuntos que cubren desde la hora de cierre del portal, uso de ascensores, basura, animales domésticos, ruidos, etc.

La ley obliga a tener un presidente de la Junta de Propietarios sobre quién recae un aluvión de tareas burocráticas que han dado origen a la aparición de empresas que gestionan la actividad de estas Juntas de Propietarios, en fin, la comunidad de vecinos, cada vez se separa más de la Junta de Propietarios, aunque, en algunas ocasiones se solapan. En cualquier caso es infrecuente que todos los miembros de una Junta de Propietarios conformen al mismo tiempo una comunidad de vecinos. Lo normal es que los propietarios se distribuyan en diversos grupos de amigos, grupos familiares más cercanos, que sí conforman en alguna manera una comunidad de vecinos. Pero, estas relaciones no están regidas por la Ley de Propiedad Horizontal.

\section{Sobre comunidad, vida social y Derecho}

Tras nuestra indagación sobre el carácter de las relaciones entre Derecho y comunidades sociológicas, la primera perplejidad que nos asalta es la relativa al signo, positivo o perturbador, de las intervenciones estatales por intermediación jurídica en su trato con las relaciones «naturales», gestadas al calor de las formas sociales de vida. No otra cosa se halla tras el omnipresente debate en torno a los efectos que la moderna 
La comunidad reconocida: familias, escuelas, y regantes...

juridificación, de mayor incidencia tras la emergencia y consolidación de los Estados de Bienestar ${ }^{23}$. Se discute a propósito de este fenómeno el carácter deletéreo o positivamente conformador que las intervenciones compensadoras del Estado providencia ejercen en la urdimbre de relaciones sociales, y que encierran la potencialidad de desplegar efectos de auténtica «colonización del mundo de la vida ${ }^{24}$ ».

Nuestra segunda reflexión parecerá seguramente polémica por su presunta antimodernidad. El Derecho, frente a los aludidos efectos deformantes o avasalladores de lo social, bien puede erigirse en instrumento de transformación social, en ariete de formas más progresivas de vida que las que las anunciadas comunidades morales traen consigo. Las inercias y los prejuicios larvados o explícitos que las comunidades arrastran consigo pueden quebrarse, en ocasiones, contra la roca firme de la legalidad. Es una posibilidad que no ha de ser desdeñada ni en su alumbramiento teórico, ni mucho menos en su virtualidad política efectiva. Tras los tan traídos y llevados modelos de desregulación, planteados como alternativa a las patologías del Estado interventor, se parapetan demasiado a menudo poderes normativos sociales que amenzan con arrumbar las últimas barreras que el Derecho erige en protección de los débiles frente al empuje avasallador de las mayorías sociológicas, travestidas indefectiblemente de mayorías morales.

Con ello no pretendemos salvaguardar el carácter benéfico a ultranza del recurso a lo jurídico estatal frente al poder autonormativo de nuestras comunidades. Ya hemos aludido más arriba a las añagazas que se esconden tras la forma jurídica de intervención. El discurso sobre los efectos perniciosos de la hiperjuridificación, la inflación normativa, el clientelismo que los Estados sociales pueden generar, el recorte de la autonomía individual, la crisis de la legitimidad contemporánea son demasiado conocidos para pretender ignorarlos ingenuamente ${ }^{25}$. En esta línea, medran por doquier las propuestas de presentar alternativas viables al Derecho, como son las conciliaciones, mediaciones y arbitrajes, que encuentran un campo abonado en el Derecho de familia, objeto de tratamiento en este escrito.

Conviene tener presente, con igual atención, que el medio jurídico, por su propia estructura, viene aquejado de limitaciones intrínsecas insalvables para atacar cualquier reforma que haga justicia a los hechos sociales más preciosos. Grimm nos recuerda que la reactividad, puntualidad y bipolaridad conforman la esencia íntima del Derecho ${ }^{26}$.

La reactividad trae a primer plano el carácter diferido de las intervenciones significa retrospectividad de las intervenciones, dilación de la respuesta jurídica, frente a las anticipaciones necesarias en toda terapia 


\section{J. José García de la Cruz Herrero y Evaristo Prieto Navarro}

eficaz. Cuando el Derecho interviene, no cabe sino levantar acta de defunción, o al menos de irreversibilidad, acerca de las realidades sociales en que la comunidad cristaliza. El Derecho no pasa en estos casos de ciencia de los remedios, de los viáticos, más bien, que administrar cuando ya todo está irremisiblemente perdido. No otra cosa sucede en el Derecho matrimonial, cuando la excepcionalidad de lo legislado se entiende en razón de las encrucijadas que la litigiosidad de las convivencias en estado terminal impone.

La puntualidad signa la fijación del Derecho a datos casuísticos, su dependencia de controversias parciales, lejos de la panorámica que capta la pluralidad cromática de la vida societaria. La intervención localizada de lo jurídico no puede sino resultar, por una parte, irremisiblemente lenta, por cuanto fía al azar de los acaecimientos sociales espontáneos su entrada en escena, y por otra, desesperantemente ineficaz, pues se recluye a los efectos, dejando inalteradas las causas profundas que los provocan. Un Derecho de familia construido a golpe de jurisprudencia moderadora de los excesos abstractivos y dogmáticos de las leyes peca precisamente de tales insuficiencias ${ }^{27}$.

La bipolaridad, por último, pero no de menor importancia, hace alusión al carácter empobrecido de las respuestas de que el Derecho dispone para enfrentar los retos sociales. Los medios limitados de sanción y tratamiento, la cortedad de la visión de los problemas en razón de estas respuestas disponibles, lastran la eficacia de las soluciones, y demandan de remedios extrajurídicos para aliviar los conflictos que la vida de la comunidad genera en su marcha.

Otra de las cuestiones importantes que cabe plantearse a propósito de las relaciones entre la forma jurídica y las comunidades sociológicas es la relativa a la extensión legítima de este contacto. La internormatividad propia del objeto de estudio, esto es, su susceptibilidad de recibir un tratamiento diferenciado desde dos sistemas de reglas diferentes en cuanto a su origen y naturaleza, nos pone ahora ante la cuestión del modelo de confluencia eficaz o aconsejable. El Derecho gradúa su intervención desde la mera declaración de efectos, la sanción de realidades que tienen lugar y desarrollo allende el mismo, y la constitución de realidades sociales sui generis, que desdibuja los contornos de la comunidad social que sirve presuntamente de trasfondo. Las dos comunidades que este trabajo trae a colación representan al mismo tiempo dos buenos ejemplos de esta interrelación diferenciada.

La familia plantea la necesidad intrínseca de una interferencia limitada por parte de un sistema normativo que le es en buena medida ajeno. Esto se percibe a través de los supuestos bien acotados en los que el 
La comunidad reconocida: familias, escuelas, y regantes...

Derecho interviene, y en la naturaleza de dicha intromisión. El Código Civil se restringe a la regulación del acceso a la institución, por mor de los efectos jurídicos que despliega en el tiempo, y que afectan tanto a los contrayentes como a terceros, muy singularmente los hijos. Una segunda juridificación es la que afecta a los regímenes económicos matrimoniales, que se justifica en razón de su potencial afectación a terceros, que eventualmente se entrecruzan en la actividad económica de los cónyuges. Por lo que hace a la vida ordinaria de la institución, el Derecho se limita a un catálogo mínimo de derechos y obligaciones correlativas, dejando por lo demás que sea la dinámica grupal la encargada de integrar las pautas normales de comportamiento. Obsérvese que cualquier intervención de lo jurídico en esta dinámica está motivada por la aparición de patologías o defectos de funcionamiento de una cotidianeidad que se presume espontánea, pero que no siempre discurre sin fricciones. Y aún así, este efecto reparador del Derecho obra sólo cuando se han agotado los recursos privativos de la institución, pues ordinariamente las comunidades sociales disponen de remedios para solventar las anomalías que su funcionamiento cotidiano suele provocar.

En el eje temporal de la vida de la familia, el Derecho sólo se dejará ver, en los casos en que esta salida sea la única disponible, en la regulación de la disolución de la institución. El Derecho, no obstante, se limita en la mayoría de los supuestos - divorcios no litigiosos- a prestar un aval jurídico, vinculante, al arreglo alcanzado entre las partes, tanto en lo que hace a la liquidación de la sociedad económica, como en lo que respecta al régimen de custodia de los hijos menores. La intervención del Derecho se encuadra sin violencias en las coordenadas de reactividad y puntualidad que detallamos más arriba, sin mayores virtualidades conformadoras de la realidad social. Pero, ¿sucede realmente así, sin más?

Si el Estado, a través de su Derecho, se limitara a dar un espaldarazo formal a todo lo dispuesto en el seno del matrimonio, sin detenerse en los vericuetos de la institución, podría llegar a signarse la mera consagración del statu quo de las relaciones familiares, hurtando su vida íntima, lo que sucede tras la bambalinas, a la mirada escrutadora de un Derecho progresista, limitador de desafueros y reinvidicador de mayores cotas de libertad e igualdad en las relaciones que pone bajo su cobertura. La promoción de la posición jurídica de las mujeres, el reequilibrio de las obligaciones mutuas entre los cónyuges, la investigación de las situaciones de violencia doméstica, y la adopción de paliativos drásticos en todos estos ámbitos, pueden interpretarse como otros tantos pasos en la dirección hacia una familia más adecuada a los ideales democráticos de igualdad y libertad, consagrados no sólo en nuestros textos constitucionales, 


\section{J. José García de la Cruz Herrero y Evaristo Prieto Navarro}

sino también en la cultura política y cívica de nuestras sociedades modernas.

El caso de la escuela es marcadamente diferente. Allí el Derecho ejerce más ampliamente su potestad normativa, modeladora de las relaciones internas entre los distintos actores que toman parte en la comunidad social. Esta, por eso mismo, merece ser contemplada como una entidad más artificial, en tanto resultado preferente de los esfuerzos del legislador, antes que como producto de relaciones sociales espontáneas al margen de la ley. La regulación extensa y tupida de la red de relaciones que tienen lugar entre los agentes del proceso educativo es buena muestra de esta intervención conformadora o constitutiva del Derecho. También han de leerse en la misma clave la estandarización de todos los actos con trascendencia académica, la regulación administrativa de lo relativo al currículo, por no hablar del sostenimiento material y la dotación de infraestructuras, que cae siempre del lado de los gestores políticos. En este sentido va dirigida nuestra afirmación de que la comunidad escolar no lo es apenas en un sentido sociológico, cuanto en una vertiente estrictamente jurídica. Las interpretaciones que tratan de rescatar los componentes comunitarios, de impregnación ética fuerte que poseen las escuelas son tributarias de una concepción obsoleta, que aún cree en la autogestión de las tradiciones por parte de los sujetos sociales informales, con grave desconocimiento de la administrativización creciente de la actividad educativa, plasmada en una inflación asfixiante de leyes y reglamentos, tanto de carácter estatal, como de ámbito comunitario.

Recapitulando, podemos decir que Derecho y comunidad son dos realidades que no necesariamente se excluyen entre sí, pero que tampoco son forzosamente complementarias, o al menos no lo son sin pagar el tributo de fricciones y desencuentros más o menos graves. Tras una época, la del bienestarismo triunfante, en que se pensó ingenuamente que el Estado podía adquirir competencias acabadas para la regeneración y control de las comunidades sociales, se ha pasado, casi sin tomar aliento, a una demanda extendida de desrregulación, o liberalización de la vida comunitaria. El Estado no puede, ciertamente, pretender erigirse en garante de una integración social ética ${ }^{28}$, basada en las virtudes de las comunidades, so pena de dañar irremisiblemente su núcleo normativo. Pero este retraimiento de la legislación en modo alguno ha de entenderse como un abandono en los brazos de la comunidad, pues tras los ideales bellamente formulados se parapeta demasiado a menudo el fantasma antimoderno de la homogeneización, de la represión autoritaria de las diferencias en estilos de vida, del ahogamiento de la rica pluralidad de formas culturales minoritarias, que al menos merecen una oportunidad de 
expresión. Y ahí sí que el Derecho no puede abdicar de su tarea: crear un marco jurídico que garantice un trato libre, e igual en derechos, entre las distintas concepciones de lo que son las comunidades sociales o, más bien, de lo que deberían ser como expresión de una convivencia más justa y enriquecedora de nuestra común humanidad.

\section{Notas}

1 Dice el Código Civil español que «hay comunidad cuando la propiedad de una cosa o de un derecho pertenece pro indiviso a varias personas" (artículo, 392). Por supuesto, este concepto reune personas en torno a un interés común, pero no tiene nada que ver con el concepto sociológico de comunidad.

2 El Derecho actual se muestra hipertrofiado en su consideración de las seudocomunidades de propietarios, entes jurídicos que aquí nosotros no consideramos como comunidades sociales de hecho, como mucho jurídicas si eso significa algo.

3 En el código civil español la sociedad no es una agrupación dirigida a cualquie fin, sino que esta figura está restringida a fines lucrativos.

4 Asociación en el sentido clásico de Tönnies. La distinción entre Comunidad y asociación en la disciplina sociológica fue enunciada por Ferdinand TöNNIEs en 1887, hay una estupenda versión en castellano del año 1979.

5 Este proceso lo hemos tratado en GARCÍA DE LA CRUZ. 1998a.

6 Pueden verse dos análisis muy claros, el primero en Alonso,1999. El segundo en Mendrás, 1999.

7 Este tema lo hemos tratado en GARCÍA DE LA CRUZ, 1990, 1995 y 1998b.

8 Recomendamos la lectura de un trabajo reciente de AlONSO, 1999, en el que se trata clara y profundamente este tema.

9 Efectivamente nos referimos al clásico debate marxista sobre la dependencia del sistema jurídico...

10 Las últimas investigaciones sobre la familia abonan la idea, el sentimiento de privacidad de esta comunidad, llegando a catalogar la fórmula matrimonial como una «intromisión de la sociead en la vida privada de los individuos...", Meil, 1991, p. 15.

11 La expresión «sin papeles» alcanza toda su crudeza en el ámbito de la inmigración ilegal, ahora bien, algo hay de esto en el matrimonio sin papeles.

12 Véase Meil, 1999.

13 Dice el Tribunal Supremo en esta sentencia que la convivencia "more uxorio" ha de desarrollarse en régimen vivencial de coexistencia diaria, estable, con permanencia temporal consolidada a lo largo de los años, practiacada de forma externa y pública con acreditadas actuaciones conjuntas de los interesados, creándose así una comunal vida amplia, intereses y fines, en el núcleo de un mismo hogar.

14 Apuntamos a las ya clasicas teorías sobre grupos de referencia y pertenencia. Situaciones que afectan a los dos cónyuges respecto a sus familias de origen.

15 Dice HenRy MENDRAS: «El derecho conónico ha retomado el principio individualista del Evangelio llevándolo a veces hasta el límite, sobre todo en lo relativo al matrimonio. La idea de que el matrimonio es el resultado del acuerdo de las voluntades de los cónyuges, y de que ellos solos, es una concepción antisocial y un rechazo al parentesco, jamás se ha construido una sociedad sobre este principio.", Mendrás, 1999, p. 19. 


\section{J. José García de la Cruz Herrero y Evaristo Prieto Navarro}

16 Véase Meil, 1999, pp. 61-74.

17 Véase Meil, 1999, pp. 75-83.

18 Este tema lo hemos abordado en GARCÍA DE LA CRUZ 1998a.

$19 \mathrm{El}$ asunto del individuo abstrácto versus individuo empírico lo hemos tratado en GARCÍA DE LA CRUZ, 1998a.

20 Puede verse un repaso histórico que subraya esta neurosis individualista de occidente en Mendrás, 1999.

21 Toda la actividad docente, curricular, y laboral les viene marcada desde fuera.

22 Sobre este diagnóstico puede verse el cuarto Informe España de la Fundación Encuentro, 1997, Capítulo III: Familia y Escuela: dos mundos que no se encuentran.

23 Son ya numerosas las obras de referencia dedicadas a la juridificación y sus problemas. Por ofrecer alguna referencia, podemos remitirnos a Günther TEUBNER (ed.), 1985, y Rüdiger VoIGT (ed.), 1980.

24 Habermas es el autor que ha acuñado esta terminología, haciendo alusión con ella a las consecuencias del empleo del Derecho, como medio de control social, en sentido parsoniano, en los mundos de la vida que conforman las provisiones de interpretaciones legítimas sobre la realidad natural y social de que los individuos disponen. Véase, Jürgen HABERMAS, 1987.

25 Tres autores que han tratado con detenimiento los problemas que el Estado de Bienestar trae consigo, tanto en lo que hace a sus rendimientos funcionales, como en lo referente a los déficits de legitimidad que lo aquejan son Klaus OFFE, 1990; Jürgen HABERMAS, 1973 y Niklas LUHMANN,1993.

26 En Dieter GrImM, 1991.

27 Un autor que ha hecho un seguimiento sociológico de las leyes de familia, en este caso del ámbito del Derecho francés, pero con lecturas válidas para todo nuestro ámbito jurídico y cultural es Jean CARBONNIER, 1998.

28 Sobre el discurso de la integración social, en sus vertientes morales, pragmáticas y éticas, ha de acudirse, en su calidad de referencias imprescidibles a Bernhard PetERs, 1993; Jürgen HABERMAS, 1992. En el ámbito español, podemos aludir, entre muchos otros, a los trabajos de Josetxo Beriain, 1996; Evaristo Prieto, 1997, y Carlos ThiebaUt, 1998.

\section{Bibliografía}

Alonso, L. «¿El retorno de la comunidad? En busca de nuevas bases sociales para la economía actual», en DuRÁN. M. A. (ed.), Las bases sociales de la economía española, Valencia, Universitat de Valencia-CSIC, pp. 139-154. 1997.

Alonso, L. Trabajo y ciudadanía. Valladolid. Editorial Trotta. 1999.

BERIAIN, J. La Integración en las sociedades modernas. Barcelona, Anthropos. 1996.

Carbonnier, J. Ensayos sobre las leyes. Madrid, Civitas. 1998.

Fundación Encuentro. 4.Informe España 1996. Madrid, Fundación Encuentro. 1997.

GARCía DE LA CRUz HERRERo, J. J. "Los nuevos movimientos sociales», en Giner. España: Sociedad y Política, Madrid, Espasa-Calpe, pp. 593-632. 1990.

García de la CRUz HeRrero, J. J. «La defensa de los intereses ante las autoridades públicas. ¿Acción colectiva o acción individual?, en REIS, n 69, enero 1995, pp. 37-67. 1995.

García DE LA CRUz HeRrero, J. J. «El axioma liberal individuo-sociedad y sus consecuencias para el control formal", en AÑoN, M. J. y otros, Derecho y Sociedad, Valencia, Tirant lo Blanch, pp.s. 425-435. 1998a. 


\section{La comunidad reconocida: familias, escuelas, y regantes...}

GARCía de la CRUZ HerRero, J. J. «El problema del modo de organización en los movimientos alternativos", en García de la Cruz. El Avance de la Paz, Madrid, Dykinson, pp. 183-208. 1998b.

GRIMM, D. "Der Wandel der Staatsaufgaben und die Krise des Rechtsstaat" en Die Zukunft der Verfassung. Frankfurt, Suhrkamp, pp. 159-175. 1991.

Habermas, J. Problemas de legitimación del capitalismo tardio. Buenos Aires, Amorrortu. 1973.

Habermas, J. Teoría de la acción comunicativa. Tomo II. Madrid, Taurus. 1987.

Habermas, J. Facticidad y validez. Madrid, Trotta. 1998.

Luhmann, N. La Teoría política en el Estado de bienestar. Madrid, Alianza.

MeIl LANDWerlin, G. La postmodernización de la familia española, Madrid, Acento Editorial. 1999.

Mendras, H. Sociología de la Europa occidental. Madrid. Alianza Editorial. 1999.

OfFe, K. Contradicciones en el Estado de Bienestar. Madrid, Alianza. 1990.

Peters, B. Die Integration moderner Gesellschaften. Frankfurt, Suhrkamp. 1993.

PRIETO, E. «Paz, conflicto y ciudadanía en las sociedades modernas», en El avance de la paz, op.cit

Teubner, G. (ed.) Dilemmas of Law in the Welfare State. De Gruyter, Berlin. 1985.

Thiebaut, C. Vindicación del ciudadano. Barcelona, Paidós. 1998.

TönNIES, F. Comunidad y asociación, Barcelona, Península. 1979.

VoIGt, R. (ed.) Verrechtlichung. Atheneum, Königsstein. 1980. 